\title{
Numerical assessment of stress concentration in Francis runner blade - crown/band junctions
}

\author{
I-C Predoiu ${ }^{1 *}, L$. Marsavina $^{2}$ and $S$. Muntean $^{3}$ \\ ${ }^{1} \mathrm{Ph}$.D. Student, Politehnica University of Timisoara, Timisoara, Romania \\ ${ }^{2}$ Professor, Politehnica University of Timisoara, Timisoara, Romania \\ ${ }^{3}$ Senior Researcher, Romanian Academy - Timisoara Branch, Romania
}

\begin{abstract}
The paper presents the results of numerical investigation for stress distribution near runner blade-crown/band junctions. Starting with the geometrical investigation of the geometries for a real turbine, different junction geometries were identified. Eight different junction geometries were numerically investigated in order to determine the stress distribution. The applied load for structural analysis was the pressure distribution, obtained from a Computational Fluid Dynamics analysis of the runner blade. The results of the stress distribution will allow to quantify the effect of different junction geometry on stress concentration and integrity of the runner.
\end{abstract}

\section{Introduction}

Hydraulic turbines are key equipments in hydropower renewable energy systems. More than $25 \%$ of the electrical energy is produced by hydropower in Romania. A lot of the hydro units were commissioned 20-40 years ago and now the assessment of integrity and durability is a problem imposed by the new demands of the energy market. Therefore, in situ experimental investigations $[1,2]$ and numerical simulations $[3-6]$ were performed on old Francis turbines to analyze the hydrodynamic phenomena associated to real hydraulic machines in order to propose new solutions for their refurbishment/rehabilitation [7-10].

The failure under fatigue of the runner blades of the Francis turbines [11-13] is focused on the region of the weld seems located at the junction between blade-crown and bladeband because those regions present a higher risk to initiate cracks leading to the catastrophic failure under fatigue [14-16]. Several authors have investigated only the junctions between the blade-crown and the blade-band considering a simplified geometry of T-joint [17-20] because of the stress concentration is located in these critical regions. The stress distribution on the runner blades is determined using fluid-solid interaction (FSI) methodology $[5,21]$.

A methodology to investigate critical regions of the runner blade corrresponding to a Francis turbine is proposed. As a result, the paper presents in the first part a geometrical analysis of the band/crown-blade joints from Francis turbines, and a real test case. Then the determination of the maximum stress distribution is shown in Fig. 1. A one way fluid structure interaction was performed based on a Computational Fluid Dynamic analysis, 
from which the pressure distribution was applied as loading on a static structural analysis. From this analysis the stress distribution $\sigma_{\text {ech }}$ on the blade was obtained and plotted near the crown/band-blade junction, Negru et. al [5]. This analysis does not take into account the stress concentration due to joint. A stress concentration analysis considering only the joint is performed considering different geometric parameters of the joint, which influence the stress concentration $\mathrm{k}_{\mathrm{t}}$. Finally, the maximum stress on the joint was obtained combining the result of the two numerical analyses.

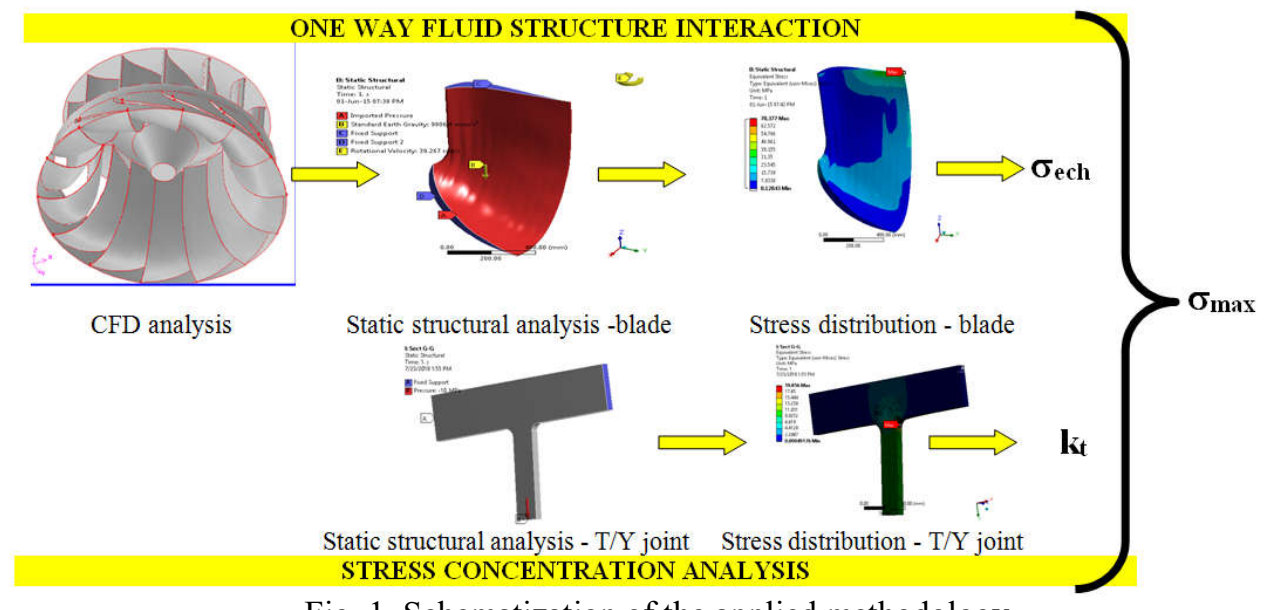

Fig. 1. Schematization of the applied methodology

\section{Geometrical analysis of the runner blade joints associated to a Francis turbine}

This paper is focused to develop a simplified methodology to evaluate the stress concentration taking into account both hydrodynamic and structural loadings. This methodology involves knowing the following data:

1. geometrical parameters of the runner;

2. operating parameters corresponding to the hydro-units;

The geometric parameters of the Francis turbine runner are crucial data in the prior evaluation of the stress concentration regions. The main geometrical parameters associated to the Francis turbines runner blades are following:

- $\mathrm{R}_{1}, \mathrm{R}_{2}$ [mm] - the fillet radii of the $\mathrm{T} / \mathrm{Y}$ joints between the runner blade (pressure side and suction side) and the band/crown;

- $\delta[\mathrm{mm}]$ - the thickness of the runner blade;

- $\alpha\left[^{\circ}\right]$ - the tilting angle of the runner blade. The value depends on the location of the section where it is measured. The angle direction of the runner blade with respect to the crown/band may be positive/negative;

- $\mathrm{D}_{2}[\mathrm{~m}]$ - the outlet diameter of the runner;

3D Francis turbine runner together with the band and crown regions is presented in Fig. 2. The details are revealing the critical regions corresponding to a Francis turbine runner together with geometric parameters defined above: 

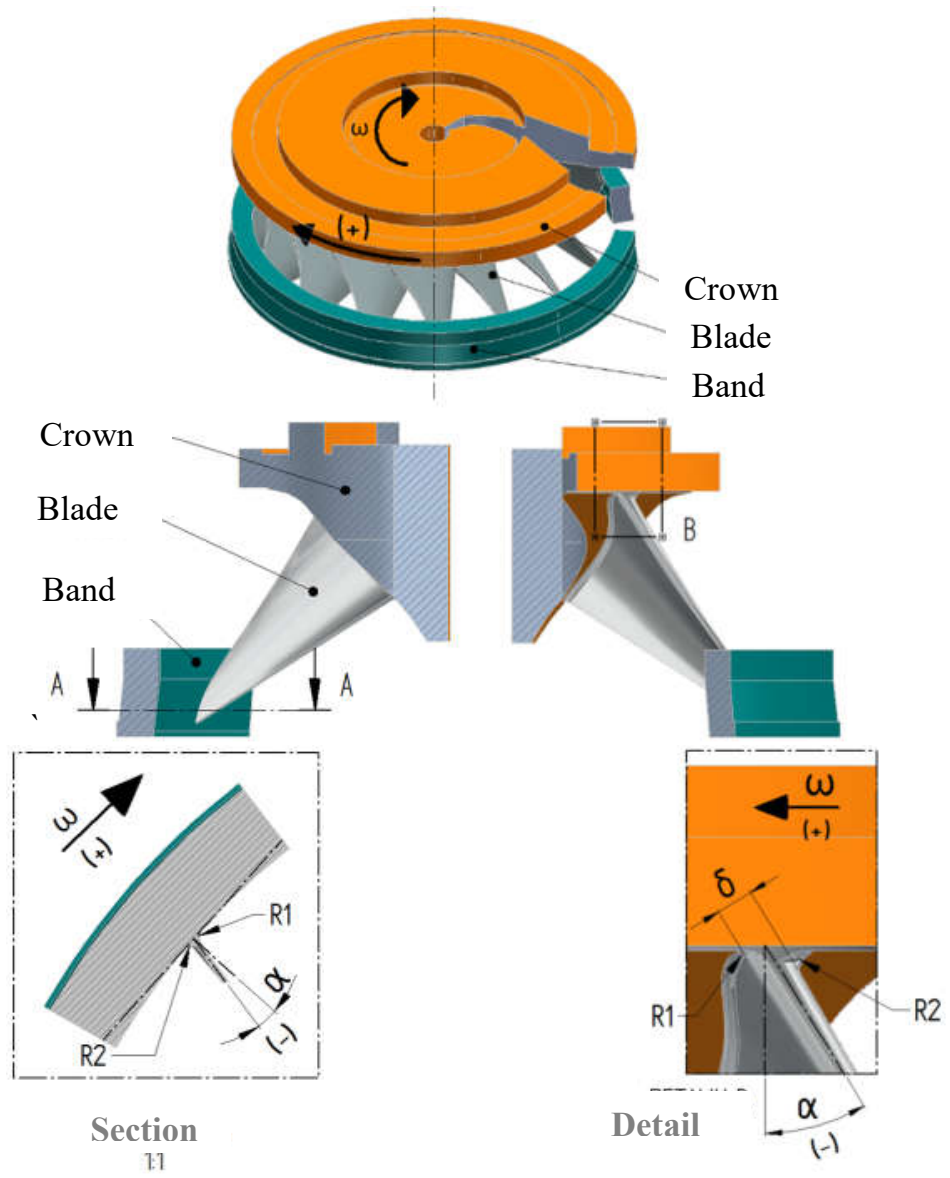

Fig. 2. Axonometric view of the Francis turbine runner (up) together with details at the band (down/left) and the crown (down/right)

\subsection{Test case}

A runner parameters corresponding to a Francis turbine with medium specific speed is selected in order to determine the stress concentration associated to the $\mathrm{T} / \mathrm{Y}$ joints between the runner blade and the band/crown.

The following parameters associated to the Francis turbine test case have been determined in Table 1: the turbine head $(H)$, the maximum discharge $\left(Q_{\max }\right)$, the maximum power $\left(P_{\max }\right)$, the outlet runner diameter $\left(D_{2}\right)$, the number of the runner blades $(Z)$, the runner speed $(n)$, the specific speed $\left(n_{s}\right)$, the characteristic speed $\left(n_{q}\right)$, the flow coefficient $(\varphi)$, the energy coefficient $(\psi)$, power coefficient $(\lambda)$, the dimensional specific speed $(v)$. The dimensionless quantities are determined according to the IEC 60193 code [22].

The Francis runner geometry together with the $\mathrm{T} / \mathrm{Y}$ joints between the runner blade and the crown (N-N at LE, F-F, G-G, H-H, I-I, K-K at TE) as well as between the runner blade and the band (A-A at LE, B-B, C-C, D-D, E-E, M-M at TE) are given in Figure 3. The geometrical data associated to the $\mathrm{T} / \mathrm{Y}$ joints for twelve locations (six at crown and six at band) displaced from leading edge (LE) to trailing edge (TE) are specified in Table 2: the thickness of the runner blade $\delta[\mathrm{mm}]$, the fillet radius between the crown/band and the runner blade on the suction side $R_{I}[\mathrm{~mm}]$, the fillet radius between the crown/band and the runner blade on the pressure side $R 2$ [mm] and the leaned angle of the runner blade $\alpha\left[^{\circ}\right]$. These sections are considered in our investigation to compute the stress concentration from the leading edge to the trailing edge of the runner blade. 
Table 1. Parameters of the Francis turbine

\begin{tabular}{|c|c|c|}
\hline Parameters & Defined according to & Value \\
& IEC code 60193 & \\
\hline Turbine head $H[\mathrm{~m}]$ & & 128.5 \\
& \multirow{2}{*}{} & 50.8 \\
Maximum discharge $Q_{\max }\left[\mathrm{m}^{3} / \mathrm{s}\right]$ & 57.5 \\
Maximum power $P_{\max }[\mathrm{MW}]$ & 2.275 \\
Outlet diameter runner $D_{2}[\mathrm{~m}]$ & & 14 \\
\cline { 1 - 1 } Number of the runner blades $Z[-]$ & & 375 \\
\hline Runner speed $n[\mathrm{rpm}]$ & $n_{q}=n Q^{0.5} H^{-1.25}$ & 70 \\
\hline Characteristic speed $n_{q}[-]$ & $\varphi=Q\left(\pi \omega R_{2 e}^{3}\right)^{-1}$ & 0.280 \\
\hline Flow coefficient $\varphi[-]$ & $\psi=2 E\left(\omega R_{2 e}\right)^{-2}$ & 1.264 \\
\hline Energy coefficient $\psi[-]$ & $\lambda=2 E Q\left(\pi \omega^{3} R_{2 e}^{5}\right)^{-1}$ & 0.353 \\
\hline Power coefficient $\lambda[-]$ & $v=\varphi^{0.5} \psi^{-0.75}$ & 0.444 \\
\hline Specific dimensional speed $v[-]$ & &
\end{tabular}

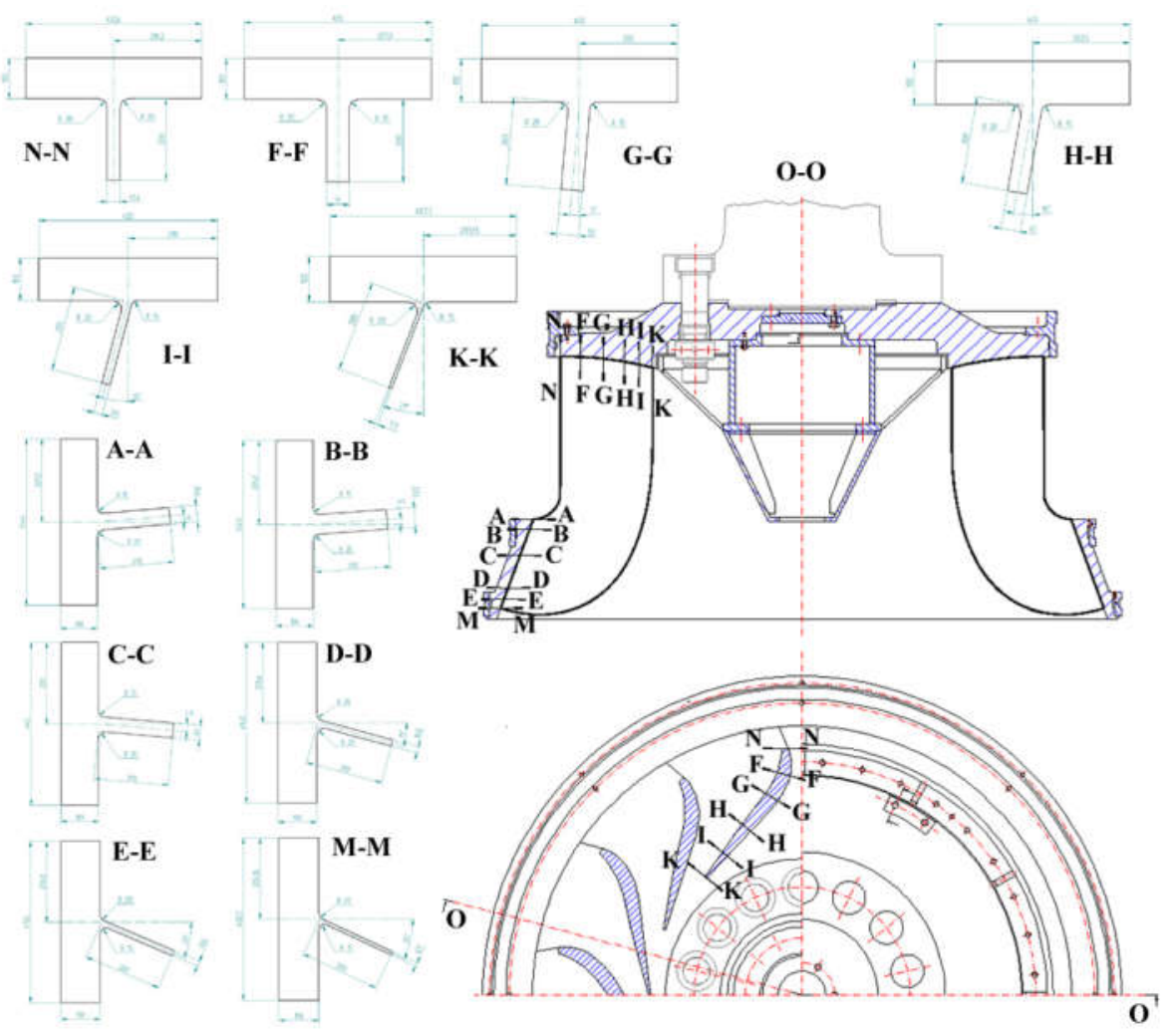

Fig. 3. Francis turbine runner with the $\mathrm{T} / \mathrm{Y}$ joints between the runner blade and the crown (N-N at LE, F-F, G-G, H-H, I-I, K-K at TE) / the band (A-A at LE, B-B, C-C, D-D, E-E, $\mathrm{M}-\mathrm{M}$ at TE) 
Table 2. Geometrical data of the $\mathrm{T} / \mathrm{Y}$ joints between the runner blade and the crown/band corresponding to the Francis runner

\begin{tabular}{|c|c|c|c|c|c|c|c|c|}
\hline Position & Section & $\begin{array}{c}\text { Thickness of the } \\
\text { runner blade } \\
\delta[\mathrm{mm}]\end{array}$ & $\begin{array}{l}\text { Dimensionless } \\
\text { length s [-] }\end{array}$ & $\begin{array}{c}\mathrm{R}_{1} \\
{[\mathrm{~mm}]}\end{array}$ & $\begin{array}{c}\mathrm{R}_{1} / \delta \\
{[-]}\end{array}$ & $\begin{array}{c}\mathrm{R} 2 \\
{[\mathrm{~mm}]}\end{array}$ & $\begin{array}{c}\mathrm{R}_{2} / \delta \\
{[-]}\end{array}$ & $\alpha^{\circ}$ \\
\hline \multirow{6}{*}{$\begin{array}{l}\text { Band } \\
\text { (J1) }\end{array}$} & A-A & 45.4 & 0.00 & 20 & 0.44 & 15 & 0.33 & -5 \\
\hline & B-B & 52.4 & 0.12 & 20 & 0.38 & 15 & 0.29 & -4 \\
\hline & $\mathrm{C}-\mathrm{C}$ & 40.0 & 0.45 & 20 & 0.50 & 15 & 0.38 & 5 \\
\hline & D-D & 16.8 & 0.86 & 20 & 1.19 & 20 & 1.19 & 15 \\
\hline & E-E & 13.6 & 0.93 & 15 & 1.10 & 20 & 1.47 & 23 \\
\hline & M-M & 8.70 & 1.00 & 15 & 1.72 & 20 & 2.30 & 25 \\
\hline \multirow{6}{*}{$\begin{array}{l}\text { Crown } \\
(\mathrm{J} 2)\end{array}$} & $\mathrm{N}-\mathrm{N}$ & 32.4 & 0.00 & 20 & 0.62 & 20 & 0.62 & 0 \\
\hline & F-F & 55.0 & 0.22 & 20 & 0.36 & 20 & 0.36 & 0 \\
\hline & $\mathrm{G}-\mathrm{G}$ & 50.0 & 0.39 & 20 & 0.40 & 15 & 0.30 & 5 \\
\hline & H-H & 45.0 & 0.58 & 20 & 0.44 & 15 & 0.33 & 10 \\
\hline & I-I & 20.0 & 0.84 & 20 & 1.00 & 15 & 0.75 & 15 \\
\hline & $\mathrm{K}-\mathrm{K}$ & 7.1 & 1.00 & 20 & 2.82 & 15 & 2.11 & 21 \\
\hline
\end{tabular}

\subsection{Analysis of the geometrical data associated to the runner blade}

The tilting angles of the $\mathrm{T} / \mathrm{Y}$ joints on twelve locations at the band ( ) and the crown (-) are plotted in Fig. 4. It can be observed that the same slope of the tilting angle is yielded for both regions. Contrary, both regions near to the leading edge corresponding to the junction of the runner blade with the band and crown are revealing a constant distribution of the tilting angle. A tilting angle of $0^{\circ}$ associated to a $\mathrm{T}$ joint is considered between the runner blade and the crown on the first fifth length of the blade from the leading edge. Also, a $\mathrm{Y}$ joint with a negative tilting angle is remarked between the runner blade and the band on the first tenth length of the blade from the leading edge. Conclusively, the first part of the blade does not follow the pattern due to a straight leading edge is imposed at the design stage. This choice leads to unfavorable hydrodynamic loading on the runner blade favoring flow separation on it, Muntean et al. [2].

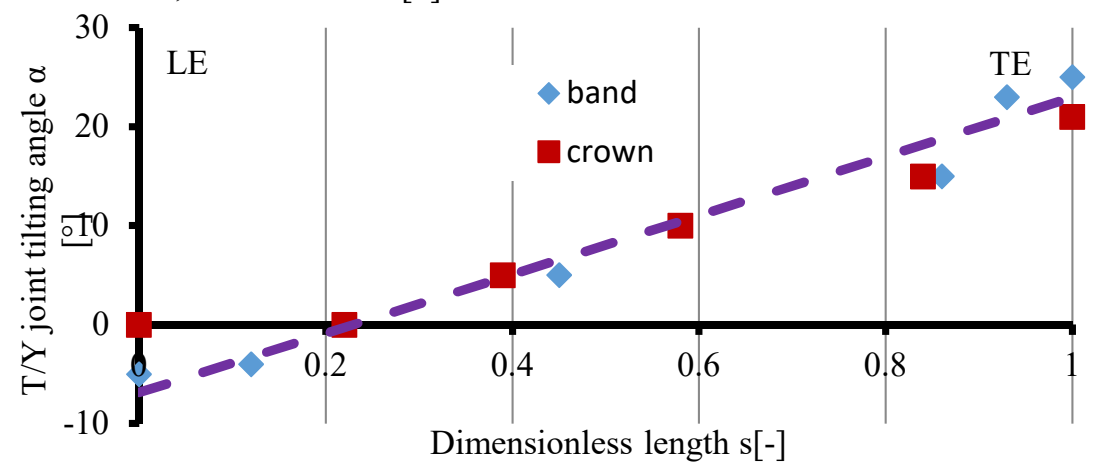

Fig. 4. Tilting angles of the $\mathrm{T} / \mathrm{Y}$ joints between the runner blade and the crown/ band.

The distribution of the dimensionless fillet radii of the $\mathrm{T} / \mathrm{Y}$ joints between the runner blade and the crown $(\mathrm{J} 1) /$ band $(\mathrm{J} 2)$ from the leading edge denoted LE $(\mathrm{s}=0)$ to the trailing edge marked with TE $(\mathrm{s}=1)$ are given in Figs. 5 and 6, respectively. 


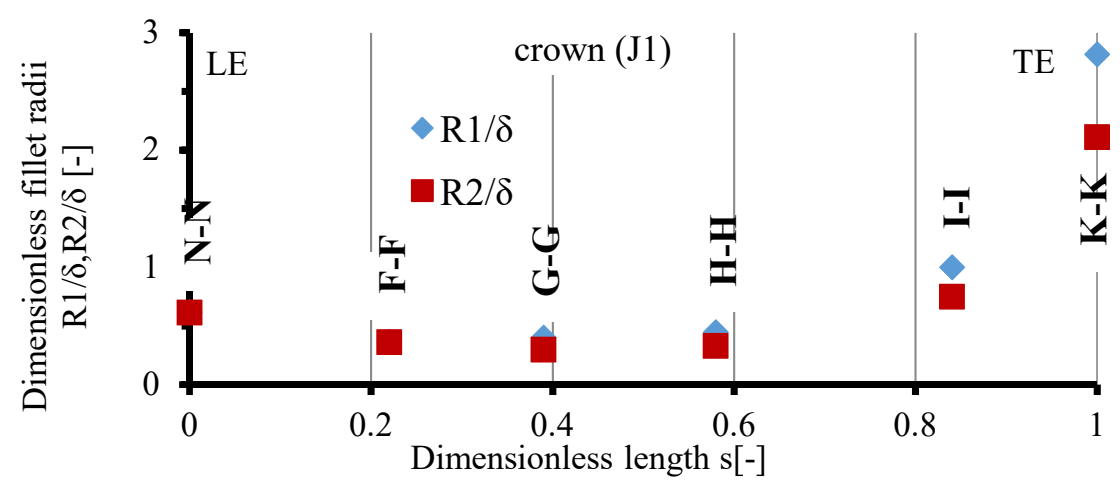

Fig. 5. The distribution of the dimensionless fillet radii (R1/ $\delta$ and $\mathrm{R} 2 / \delta$ ) of the $\mathrm{T} / \mathrm{Y}$ joints between the runner blade and the crown $(\mathrm{J} 1)$ from the leading edge $(\mathrm{s}=0)$ to the trailing edge $(\mathrm{s}=1)$

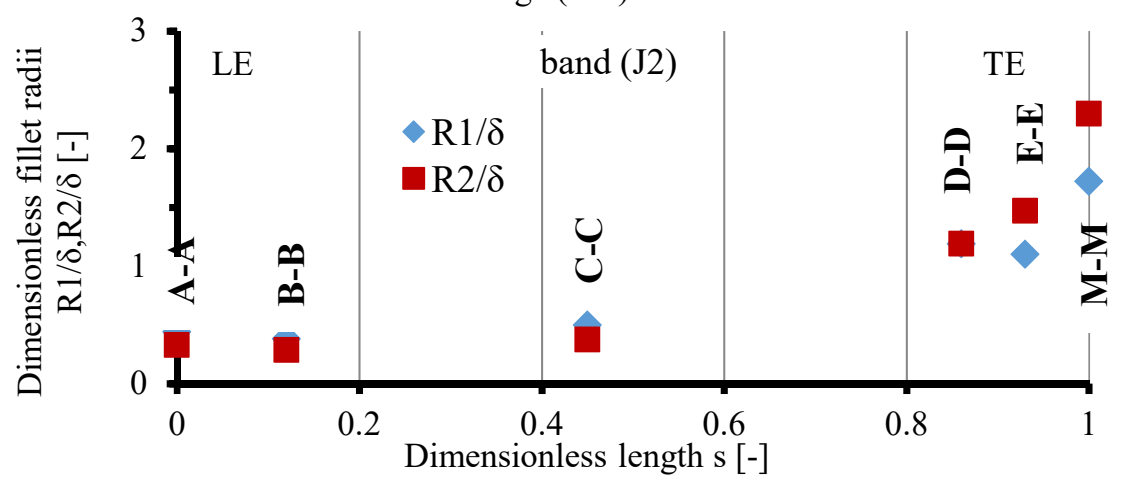

Fig. 6. The distribution of the dimensionless fillet radii (R1/ $\delta$ and $\mathrm{R} 2 / \delta$ ) of the $\mathrm{T} / \mathrm{Y}$ joints between the runner blade and the band (J2) from the leading edge (LE) ( $\mathrm{s}=0)$ to the trailing edge $(\mathrm{TE})(\mathrm{s}=1)$

The same tendency is observed for the distribution of the dimensionless fillet radii associated to the $\mathrm{T} / \mathrm{Y}$ joints between the runner blade and the crown (J1) / band (J2) from the leading edge to the trailing edge. A distribution of the dimensionless fillet radii with low constant value is determined from the leading edge $(\mathrm{A}-\mathrm{A} / \mathrm{N}-\mathrm{N})$ up to beyond the half length of the blade. The larger values of the dimensionless fillet radii are identified on the trailing edge. The maximum value is found near to the crown (M-M) due to the runner blade is thinnest in this region.

\section{Numerical stress analysis in $T / Y$ joints}

Three-dimensional FE analysis was performed on the T and Y joints, identified in the previous chapter, using general-purpose FE software ANSYS-Workbench. Twelve geometries were generated corresponding to crown-blade and band-blade junctions. The considered boundary conditions were fixed support for the crown and band and a pressure load of $\sigma_{\text {appl }}=10 \mathrm{MPa}$ applied along the blade, Fig. 7a.

The models were meshed with 8-noded solid elements (for example for G-G geometry 39240 elements connected in 181693 nodes, Fig. 7b) having the average element size of 1 $\mathrm{mm}$ and assuring a minimum 6 elements on blade thickness. 


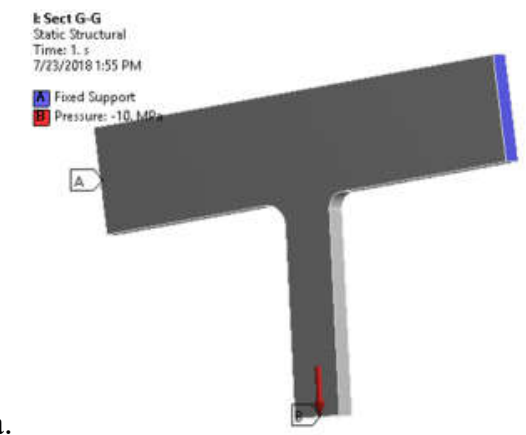

a.

Fig. 7. Structural stress analysis of T/Y-joints. Problem definition: boundary conditions (a) and mesh (b).

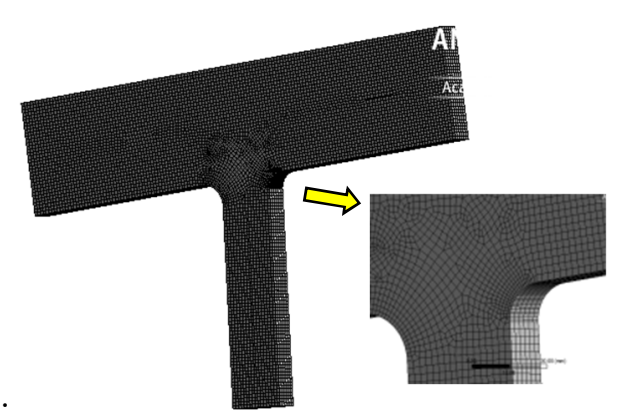

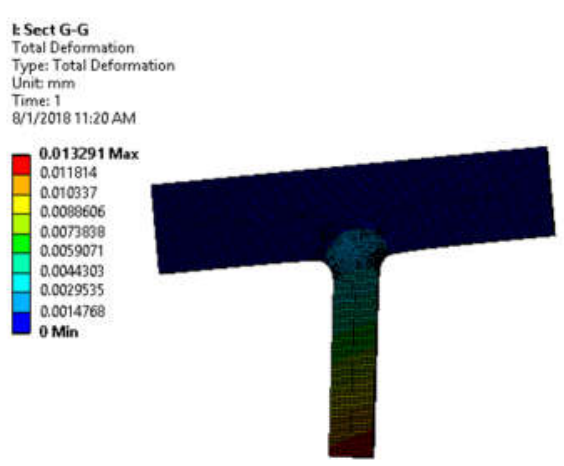

a.

b.

Fig. 8. Structural stress analysis of T/Y-joints. Results: total displacement (a) and Von Misses equivalent stress (b).

From each analysis the total displacement and Von Miss equivalent stress were obtained as results in Fig. 8. The maximum load $\sigma_{\max }$ was identified on the both sides: pressure side (PS) and suction side (SS) of the blade near to the fillet between blade and crown/band. Than the stress concentration factor was calculated as:

$$
k_{t}=\sigma_{\max } / \sigma_{a p p l}
$$

The variation of the stress intensity factors versus the dimensionless length is plotted in Fig. 9. A third order polynomial interpolation was performed in order to describe the variation of the stress concentration in $\mathrm{T} / \mathrm{Y}$ joints between the runner blade and the crown (J1)/band (J2) on the pressure side (PS) and the suction side (SS), respectively.

The coefficients $\left(a_{3}, a_{2}, a_{1}\right.$ and $\left.a_{0}\right)$ of the polynomial function associated to the stress concentration together with $\mathrm{R}^{2}$ parameter in order to assess the fit accuracy on $T / Y$ joints between the runner blade and the crown (J1)/ band (J2) are given in Table 3.

Table 3. Coefficients of the polynomial fit and $\mathrm{R}^{2}$ parameter on the $\mathrm{T} / \mathrm{Y}$ joints between the runner blade and the crown $(\mathrm{J} 1) /$ band $(\mathrm{J} 2)$

\begin{tabular}{|c|c|c|c|c|c|c|}
\hline \multirow{2}{*}{ Location } & Side & $\mathrm{a}_{3}$ & $\mathrm{a}_{2}$ & $\mathrm{a}_{1}$ & $\mathrm{a}_{0}$ & $\mathrm{R}^{2}$ \\
\hline \multirow{2}{*}{ crown (J1) } & PS & -3.0657 & -1.8606 & 1.0879 & 1.4111 & 0.9920 \\
\cline { 2 - 7 } & $\mathrm{SS}$ & 2.5001 & -4.5487 & 1.6361 & 1.4364 & 0.9630 \\
\hline \multirow{2}{*}{ band (J2) } & PS & 0.1234 & -1.4592 & 1.1354 & 1.6446 & 0.9904 \\
\cline { 2 - 7 } & $\mathrm{SS}$ & 1.1636 & -1.7370 & -0.0527 & 1.6683 & 0.9854 \\
\hline
\end{tabular}



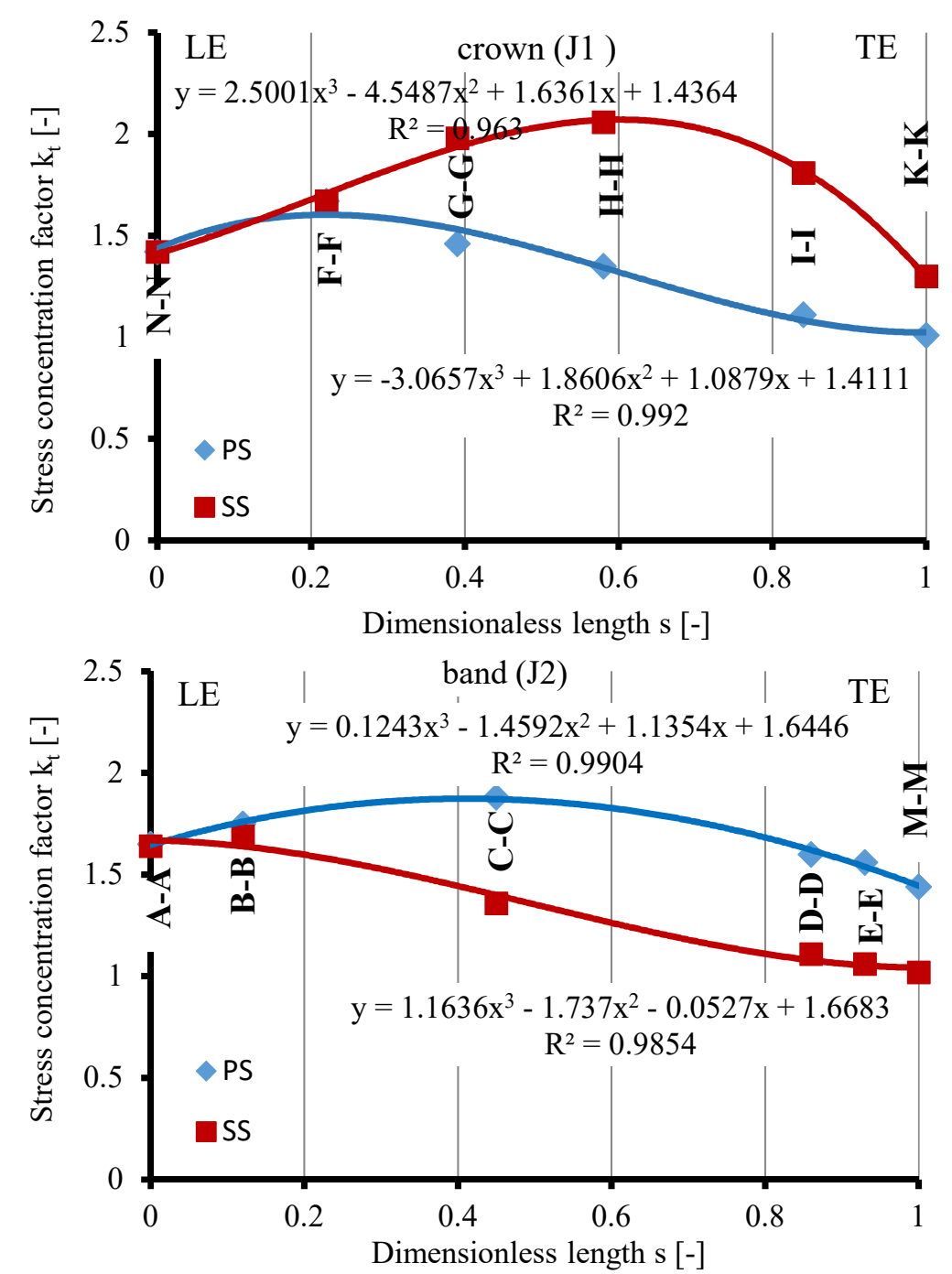

Fig. 9. Stress intensity factors variation versus dimensionless length on the $\mathrm{T} / \mathrm{Y}$ joints between the runner blade and the crown (J1) (up)/ band (J2) (down).

The stress distribution on the Francis runner blade without fillet radii were numerically computed on both suction side (SS) and pressure side (PS) by Negru et al. [5] for seven operating points from partial load conditions (PL1, PL2, PL3, PL4), best efficiently point (BEP) to overload (OL1, OL2) at constant head. The main parameters associated to each operating point selected in our CFD study are given in Table 4. The dimensionless discharge values are determined taking into account the value corresponding to the best efficiency point. The relative values of the guide vane opening $\left(\mathrm{a}_{0}\right)$ and output mechanical power $(\mathrm{P})$ at the turbine shaft are computed with respect to the maximum values due to these two values are known in the hydropower plant. One can observe that the output mechanical power of the turbine is varied from 55\% of $\mathrm{P}_{\mathrm{Max}}$ at PL1 to full power at OL2. As a result, the static load on the runner blade is changed for each operating point leading to various stress distribution maps on both sides (SS/PS) of the runner blade as well as to different locations of the maximum stress value. 
Therefore, the stress distributions on SS/PS of the runner blade without the joint are plotted in Figs. 10 and 11 with long dashed lines colored with blue/red. These numerical results are identical with data presented by Negru et al. [5]. Next, the stress distributions on the Francis runner blade are determined taking into account the fillet radii based on the distribution of the stress concentration factor plotted in Fig. 9. As a result, the stress distributions on SS/PS modified with the stress concentration are marked with solid lines in Figs. 10 and 11 for all seven operating point. It is added letter "c" from "correction" to the labels from Figs. 10 and 11 for all stress distributions obtained taking into account the fillet radii. The contribution of the stress concentration is quantified in both figures by the distance between the solid line and the long dashed line. The location of the maximum stress on SS/PS is marked with $\bullet / \mathbf{\square}$ in figures to emphasize its change with operation point.

Table 4. The parameters associated to the operating points (OPs) selected in CFD analysis

\begin{tabular}{|l|c|c|c|c|}
\hline OP & $\begin{array}{c}\text { Dimensionless } \\
\text { discharge Q/QBEP [-] }\end{array}$ & $\begin{array}{c}\text { Operating point } \\
\text { regime }\end{array}$ & $\begin{array}{c}\text { Relative guide vane } \\
\text { opening } \mathrm{a}_{0} / \mathrm{a}_{0 \mathrm{Max}}[\%]\end{array}$ & $\begin{array}{c}\text { Relative power } \\
\mathrm{P} / \mathrm{P}_{\text {Max }}[\%]\end{array}$ \\
\hline PL 1 & 0.6823 & Part load & 58.754 & 54.888 \\
\hline PL 2 & 0.7583 & Part load & 64.630 & 63.017 \\
\hline PL 3 & 0.8541 & Part load & 70.505 & 72.518 \\
\hline PL 4 & 0.9281 & Part load & 76.381 & 80.204 \\
\hline BEP & 1.0 & $\begin{array}{c}\text { Best efficiency } \\
\text { point }\end{array}$ & 82.256 & 86.794 \\
\hline OL 1 & 1.066 & Over load & 88.132 & 91.974 \\
\hline OL 2 & 1.134 & Over load & 100 & 100 \\
\hline
\end{tabular}
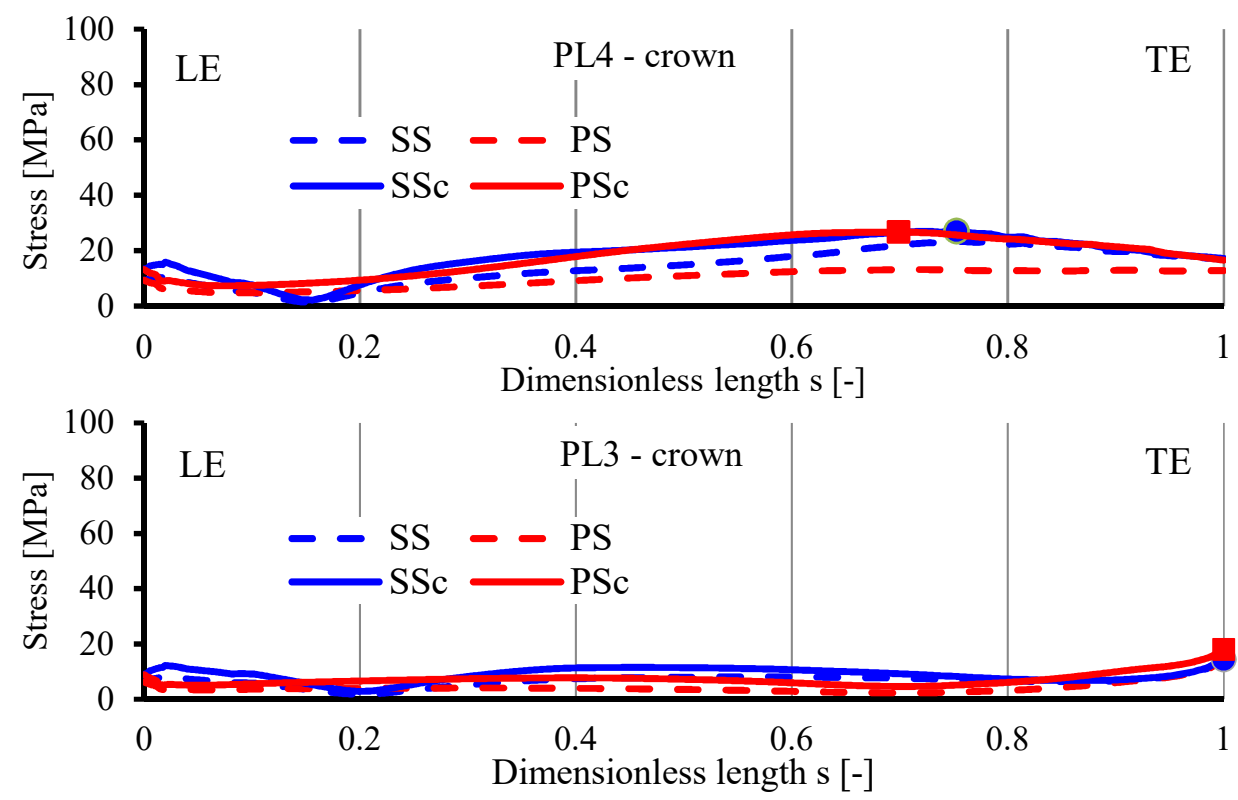

Fig. 10. Stress distribution along to the junction J1 between the runner blade and the crown for seven operating points from partial load conditions (PL4) to overload conditions (OL2). 

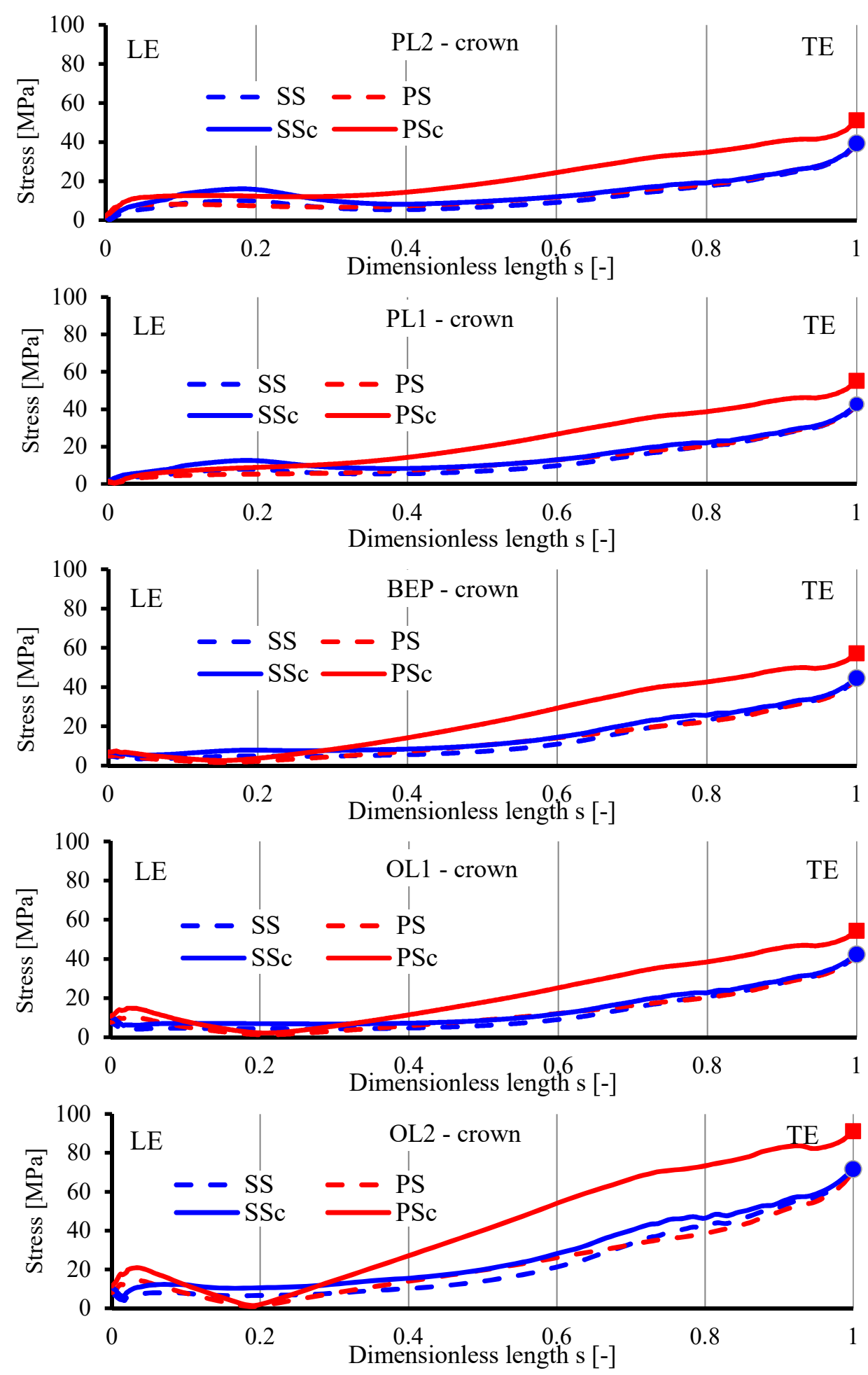

Fig. 10 (continuous). Stress distribution along to the junction J1 between the runner blade and the crown for seven operating points from partial load conditions (PL4) to overload conditions (OL2). 

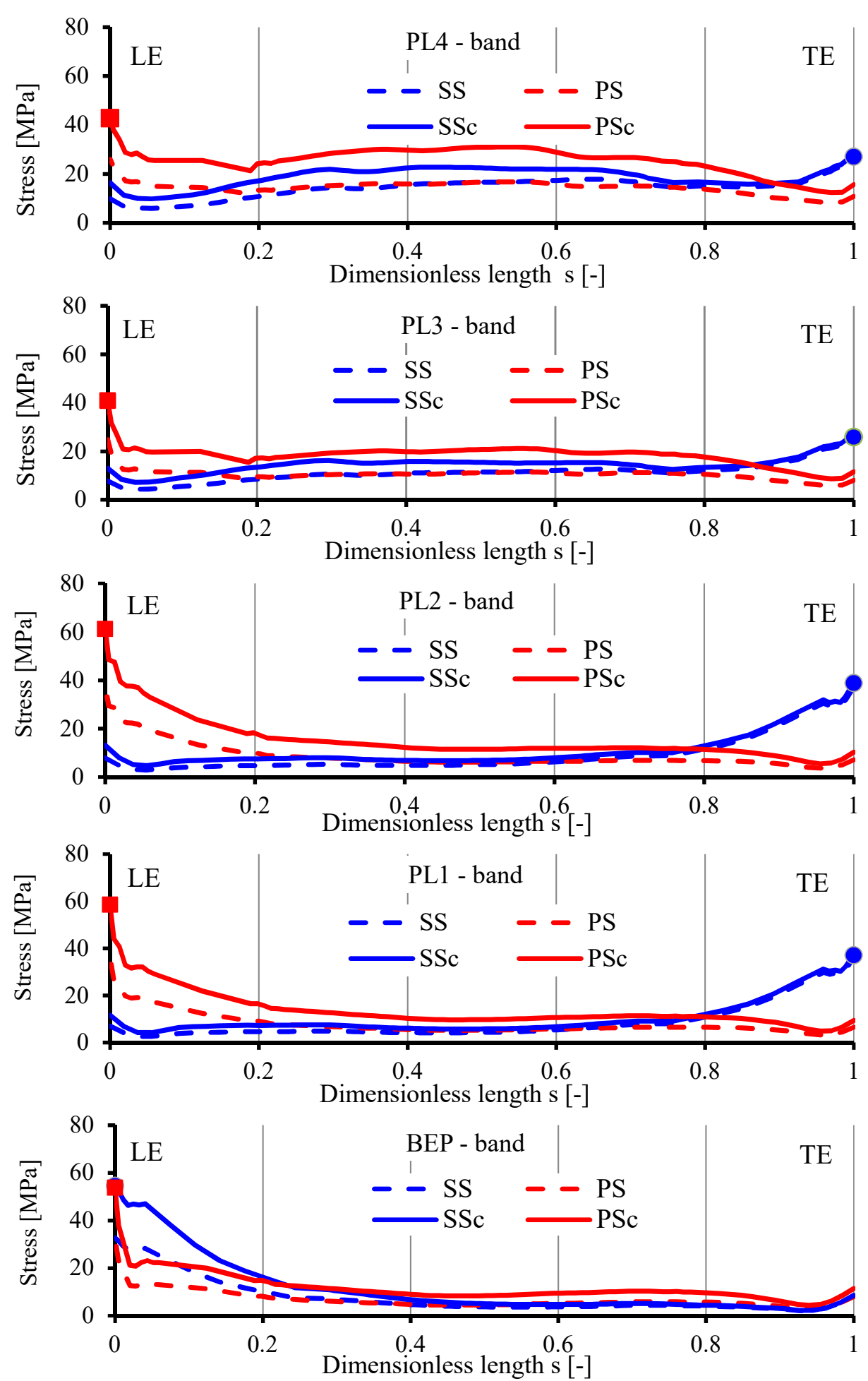

Fig. 11. Stress distribution along to the junction J2 between the runner blade and the band for seven operating points from partial load conditions (PL4) to overload conditions (OL2). 

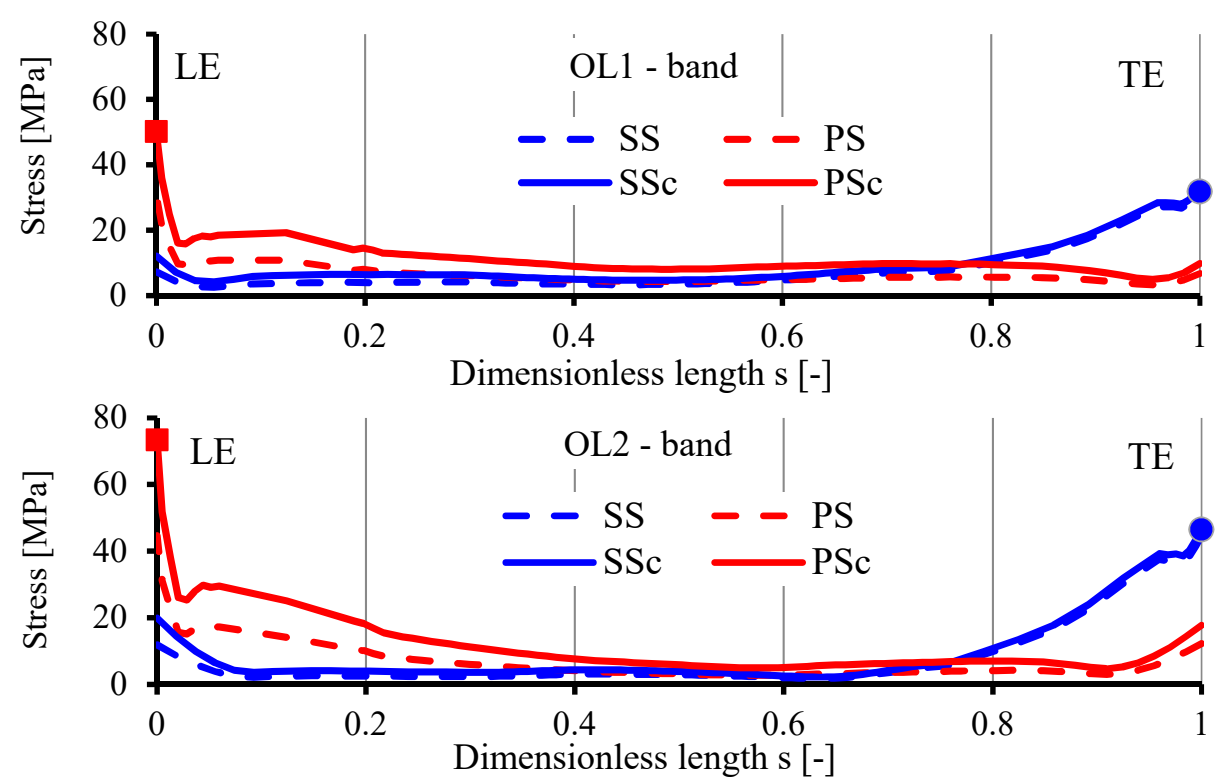

Fig. 11. (continuous). Stress distribution along to the junction $\mathrm{J} 2$ between the runner blade and the band for seven operating points from partial load conditions (PL4) to overload conditions (OL2).

\section{Conclusion}

The paper presents a methodology to determine the stress distribution in the crown/ band - blade junctions form Francis turbine. The methodology consists in one-way FSI in order to determine the pressure distribution (CFD analysis) and a structural analysis on blade resulting the stress distributions. This solution is multiplied by the stress concentration factor obtained using static structural analysis on different types of joints ( $T$ and Y) from the crown/band - blade junctions. Seven regimes corresponding to the Francis turbine operation were investigated yielding equivalent Von Mises stress distributions on the runner blade. As a general observation all stress levels are below the yield strength of the blade material (T10CuNiCr180), [15].

The maximum static stress near the band was obtained for the OL 2 regime on the pressure side on the leading edge, respectively for the suction side for the same regime at the trailing edge. The same stress distribution results for partial load regimes PL1-PL4. For the BEP regime maximum stress is on the leading edge for both SS and PS.

The maximum equivalent stress near the crown was obtained also for OL2 regime but on the trailing edge for both suction side and pressure side. The same behavior could be observed for the other regimes with exception of PL1 regime where the maximum stress occurs at $\mathrm{s}=0.7-0.75$.

\section{Acknowledgement}

Dr. Muntean S. have been supported by research program of the Hydrodynamics and Cavitation Laboratory, Center for Fundamental and Advanced Technical Research, Romanian Academy - Timisoara Branch. 


\section{References}

[1] Baya A., Muntean S., Campian V.C., Cuzmos A., Diaconescu M., Balan G., (2010) Experimental investigations of the unsteady flow in a Francis turbine draft tube cone, IOP Conference Series-Earth and Environmental Science 12, 012007.

[2] Muntean S., Susan-Resiga R., Câmpian V.C., Dumbravă C., Cuzmoş A. (2014) In situ unsteady pressure measurements on the draft tube cone of the Francis turbine with air injection over an extended operating range, UPB Scientific Bulletin, Series D: Mechanical Engineering 6(3), pp. 173-180.

[3] Muntean S., Baya A., Susan-Resiga R., Anton I., (2009) Numerical Flow Analysis into a Francis Turbine Runner with Medium Specific Speed at Off - Design Operating Conditions, Acta Technica Napocensis, Series: Applied Mathematics and Mechanics, 52, II, p. $325-334$

[4] Muntean S., Ninaci I., Susan-Resiga R., Baya A., Anton I. (2010) Numerical analysis of the flow in the old Francis runner in order to define the refurbishment strategy, UPB Scientific Bulletin, Series D: Mechanical Engineering, 72(1) p. 117-124

[5] Negru R., Muntean S., Marsavina L., Susan-Resiga R., Pasca N., (2012) Computation of stress distribution in a Francis turbine runner induced by fluid flow, Computational Materials Science 64, p. 253-259.

[6] C. Müller, T. Staubli, R. Baumann, E. Casartelli, (2014) A case study of the fluid structure interaction of a Francis turbine, IOP. Conf. Ser.: Earth Environ. Sci. 22032053.

[7] Sallaberger M., Michaud Ch., Born H., Winkler St. and Peron M. (2001) Design and Manufacturing of Francis Runners for Rehabilitation Projects, Hydro 2001, Riva del Garda

[8] Sotnikov A.A. (2001) Water Turbines at Bratsk HES: Design, Use and Upgrading, Hydrotechnical Construction, 35(10), p. 507-511.

[9] Papillon B., Gagne J.-L., Giroux S., Sabourin M. (2002) Turbine rehabilitation: Chutedes-Passes case study, HydroVision, Portland, Oregon.

[10] Muntean S., Susan-Resiga R., Goede E., Baya A., Terzi R., Tîrşi C. (2016) Scenarios for refurbishment of a hydropower plant equipped with Francis turbines, Renewable Energy and Environmental Sustainability, 1, 30, p. 1- 6.

[11] Gagnon M., Tahan A., Bocher P., Thibault D., (2013) A probabilistic model for the onset of High Cycle Fatigue (HCF) crack propagation: Application to hydroelectric turbine runner. International Journal of Fatigue 47 p. 300-307

[12] Gagnon M., Tahan A., Bocher P., Thibault D., (2013) On the Fatigue Reliability of Hydroelectric Francis Runners. Procedia Engineering. 66 p. 565-574.

[13] Gagnon M., Tahan A., Bocher P., Thibault D. (2014) Influence of load spectrum assumptions on the expected reliability of hydroelectric turbines: A case study, Structural Safety, 50, p. 1-8.

[14] Fisher R.K., Seidel U., Grosse G., Gfeller W., Klinger R., (2002) A case study in resonant hydroelastic vibration: the causes of runner cracks and the solutions implemented for the Xiaolangdi hydroelectric project, Proceedings of the XXI IAHR Symposium on Hydraulic Machinery and Systems, Lausanne, Switzerland.

[15] Frunzăverde D., Muntean S., Mărginean G., Câmpian V.C., Marşavina L., (2010) Failure analysis of a Francis turbine runner, IOP Conf. Series: Earth and Environmental Science, 12(1), 012115 p. 1-9.

[16] Luna-Ramírez A., Campos-Amezcua A., Dorantes-Gómez O., Mazur-Czerwiec Z., Muñoz-Quezada R., (2016) Failure analysis of runner blades in a Francis hydraulic turbine-Case study, Engineering Failure Analysis, 59, p 314-325.

[17] Huth H.-J. (2005) Fatigue Design of Hydraulic Turbine Runners, PhD thesis, Norwegian University of Science and Technology (NTNU), Trondheim, Norway,

[18] Carpinteri A., Brighenti R., Huth H.-J., Vantadori S. (2005) Fatigue growth of a surface crack in a welded T-joint International Journal of Fatigue 27(1) pp. 59-69. 
[19] Carpinteri A., Ronchei C., Scorza, D.,Vantadori S. (2015) Fracture mechanics based approach to fatigue analysis of welded joints, Engineering Failure Analysis, 49, pp. 67-78.

[20] Pasca N., Marsavita L., Negru R., Muntean S. (2013) Estimation of the Stress Intensity Factor for 3D Cracked T - Joint. In: Jármai K., Farkas J. (eds) Design, Fabrication and Economy of Metal Structures, pp. 273-280. Springer ISBN: 978-3-642-36690-1 DOI: 10.1007/978-3-642-36691-8_41

[21] Saeed R.A., Galybin A.N., Popov V., (2010) Modelling of flow-induced stresses in a Francis turbine runner, Advanced in Engineering Software, 41, p. 1245-1255.

[22] IEC 60193 (1999). Hydraulic Turbines. Storage Pumps and Pump-Turbines - Model Acceptance Tests. International Electrotechnical Commission (2nd ed.) Geneva, Switzerland. 